\title{
O lúdico no ambiente da classe hospitalar: um estudo de revisão
}

\author{
Playfulness in the environment of hospital classes: a review
}

Lo lúdico en el ambiente de la clase hospitalaria: un estudio de revisión

Recebido: 14/12/2018

Aprovado: 27/05/2019

Publicado: 01/07/2019

\author{
Júlio César Rodrigues ${ }^{1}$ \\ Regina Maria Rovigati Simões ${ }^{2}$ \\ Elaine Prodocimo ${ }^{3}$
}

Esta é uma revisão integrativa que teve como objetivo verificar o que foi produzido acerca do lúdico no ambiente da classe hospitalar entre o segundo semestre de 2015 e 2017. Foram encontrados 16 estudos nas bases de dados do Google Acadêmico, Scielo e Plataforma Capes. Esses estudos se organizaram em duas categorias: o lúdico como humanização e como processo de aprendizagem no contexto da classe hospitalar. Os achados mostraram que o lúdico pode contribuir no processo de aprendizagem e humanização no contexto da classe hospitalar, apontando as tendências tecnológicas como fator contribuinte para tais processos.

Descritores: Ensino; Atividades de Lazer; Criança hospitalizada.

This is an integrative review that aims to verify works published about the ludic in hospital classes between the second semester of 2015 and 2017. Sixteen studies were found in the databases Google Scholar, Scielo, and Capes. These researches were separated in two categories: the ludic as humanization and as a process of learning in the context of hospital classes. The findings have shown that the ludic can contribute to the processes of learning and humanization in the context of hospital classes, indicating how technological trends contribute for the processes.

Descriptors: Teaching; Leisure activities; Child, Hospitalized.

Esta es una revisión integrativa que tuvo como objetivo verificar lo que fue producido acerca de lo lúdico en el ambiente de la clase hospitalaria entre el segundo semestre de 2015 y 2017. Fueron encontrados 16 estudios en las bases de datos del Google Académico, Scielo y Plataforma Capes. Estos estudios se organizaron en dos categorías: lo lúdico como humanización y como proceso de aprendizaje en el contexto de la clase hospitalaria. Los hallazgos mostraron que lo lúdico puede contribuir en el proceso de aprendizaje y humanización en el contexto de la clase hospitalaria, apuntando las tendencias tecnológicas como factor contribuyente para tales procesos.

Descriptores: Enseñanza; Actividades recreativas; Niño hospitalizado.

1. Profissional de Educação Física. Especialista em Educação Infantil. Mestre em Educação Física. Doutorando em Educação Física pela Universidade Estadual de Campinas (UNICAMP), Campinas, SP, Brasil. ORCID: 0000-0001-6551-393X E-mail: jc_rodrigues@yahoo.com

2. Profissional de Educação Física. Especialista em Motricidade Humana. Mestre em Educação. Doutora em Educação Física. Pós-Doutora em Ciência do Movimento Humano. Docente do Programa de Pós-Graduação em Educação e no Programa de Pós Graduação em Educação Física da Universidade Federal do Triângulo Mineiro (UFTM), Uberaba, MG, Brasil. ORCID: 0000-0002-3135-9425 E-mail: rovigatisimoes@uol.com.br

3. Profissional de Educação Física. Mestre em Educação Especial. Doutora em Educação Física. Pós-Doutora em Psicologia do Desenvolvimento. Livre Docente do Programa de Pós-Graduação em Educação Física da UNICAMP, Campinas, SP, Brasil. ORCID: 0000-0002-2500-3668 E-mail: elaine@fef.unicamp.br 


\section{INTRODUÇÃO}

$\mathbf{S}$ abe-se que o processo de internação de crianças e adolescentes se configura como algo que causa angústia, tanto para aquele que é hospitalizado quanto para seus familiares. Para diminuir tais sentimentos, uma das ações realizadas em todo o mundo foi a criação do ambiente educacional denominado "classe hospitalar". A educação para crianças hospitalizadas se apresenta como mais uma possibilidade no leque das práticas educativas, sobretudo como diferencial no processo de inclusão de crianças em situação de risco ${ }^{1}$.

Historicamente, as primeiras iniciativas de educação em ambientes hospitalares ocorreram em 1935, na cidade de Paris, com Henri Sellier, ministro da saúde da França na época. Para ele, as instituições assistencialistas poderiam acolher crianças órfãs, e assim o fez, estruturando todo o sistema de controle de serviços de higiene ${ }^{2}$ para acolher esse público. Essa ideia representou um avanço e se estendeu por toda a Europa e Estados Unidos. Com o início da segunda guerra mundial, surgiu também a necessidade de criar instituições que oferecessem atendimento aos órfãos de guerra ou das crianças separadas de seus pais ${ }^{3}$.

Os anos se passaram e, com eles, o modelo da classe hospitalar sofreu mudanças. Atualmente, essa prática se configura como uma escola dentro dos hospitais, na qual os professores realizam projetos pedagógicos para crianças internadas em idade escolar. No Brasil, a ação educacional em ambiente hospitalar data de 1902, quando foi introduzida no Hospício Nacional de Alienados no Rio de Janeiro. Nesse período, as crianças eram atendidas no Pavilhão-Escola Bourneville 4 .

A inclusão de crianças e adolescentes hospitalizados consolidouse legalmente no país por meio das classes hospitalares, que propiciam a continuidade do processo educacional, tendo em vista os sentimentos, as necessidades e os direitos da criança hospitalizada, que merece respeito e compreensão. Cumpre à educação hospitalar, ao mesmo tempo em que trata das questões pedagógicas, fortalecer os vínculos humanos e as relações sociais, com vistas à promoção da saúde das crianças e adolescentes que estão internados 5 .

No Brasil, a educação escolar dentro dos hospitais consolidou-se atrelada à educação especial, que tinha o intuito de atender crianças deficientes físicas ou mentais. Esse foi o possível embrião do ensino especial no país, sendo a classe hospitalar uma modalidade da Educação Especial e Inclusiva que atendia as crianças hospitalizadas e que, por esse motivo, não frequentavam a escola regular6.

Esse ambiente conta com o apoio dos espaços das brinquedotecas que, segundo a Lei Federal no 11.104 , são espaços obrigatórios de saúde, que oferecem atendimento pediátrico em regime de internação, tornando-se um local onde o lúdico entra em ação, deixando o ambiente de internação mais favorável para o aprendizado, uma vez que pode-se trabalhar em comunhão com a classe hospitalar ${ }^{7}$. Brincar é um direito de qualquer criança, mesmo daquelas que se encontram hospitalizadas. A criança que está em um hospital tem que mudar seus hábitos radicalmente, fica afastada da escola, de sua casa, de seus amigos e brinquedos, e, dependendo da enfermidade, é privada até de brincar.

As professoras da classe hospitalar podem desenvolver diversas atividades com as crianças, com o agravante delas dependerem das suas condições clínicas e de sua disposição. Comumente, essas atividades assumem um caráter lúdico e abrem espaço para recreação e interação entre as crianças, ao mesmo tempo em que desmistificam a ideia do hospital como um ambiente frio e triste, uma vez que a educação em hospitais focaliza o estudante como paciente na perspectiva de sujeito inventivo, que consegue se adaptar ao novo e sair das amarras do estado de vitimização ${ }^{8}$.

Verificou-se, no período de 2011-2015, a ausência de políticas financeiras e a precariedade da estrutura física como dois dos principais desafios que as professoras da classe hospitalar enfrentavam ao realizar o trabalho pedagógico voltado para o lúdico. 
Constatou-se também que o brincar e o aprender podem ser trabalhados numa ação pedagógica conjunta, visando a aprendizagem dos sujeitos participantes hospitalizados, de forma que o lúdico se torna um intercessor do processo de ensino e de aprendizagem ${ }^{8}$.

A proposição de atividades lúdicas ao longo do processo de hospitalização de crianças e adolescentes é uma estratégia que se mostrou efetiva para diminuir as vulnerabilidades emocionais advindas da internação, sendo o medo e a ansiedade sentimentos recorrentes nessa condição. Quando as crianças ou adolescentes internados se deparam com um espaço dedicado ao lúdico, podem amenizar suas tensões, isto é, o medo e a ansiedade dão espaço para momentos de prazer e interação com o outro, pois nesses locais há também uma preocupação com o bem-estar do indivíduo 9 .

São perceptíveis as mudanças ocorridas na área da educação ao longo do tempo, e notórias as ressignificações das práticas docentes que buscam uma melhoria no processo de aprendizagem. Isso se deve, entre outros fatores, à inclusão e/ou fortalecimento do lúdico no contexto escolar, o que trouxe resultados satisfatórios por meio de possibilidades de criação, adaptação e reinvenção de forma divertida, estimulando o desenvolvimento no que se refere à aprendizagem e à subjetividade de crianças para e com a realidade.

Assim, os jogos e as brincadeiras superam a ideia de meros passatempos ou coisas "não sérias" e passam a se tornar algo relevante, que envolve a participação ativa de professores e alunos ${ }^{10,11 .}$

Nesse sentido, mostra-se pertinente fazer um levantamento sistemático dos estudos produzidos a respeito do lúdico no contexto hospitalar, tendo como base o seguinte questionamento: Como o lúdico no contexto da classe hospitalar vem sendo tratado nas produções científicas?

Em busca de responder a essa problemática, o presente estudo tem como objetivo verificar o que foi produzido acerca do lúdico no ambiente da classe hospitalar entre o segundo semestre de 2015 a 2017.

\section{MÉTODO}

Esta é uma revisão integrativa ${ }^{12}$ sobre o lúdico no contexto da classe hospitalar. Estudos de revisão integrativa contribuem para 0 processo de sistematização e análise dos resultados, visando a compreensão de um tema específico e respeitando as fases do processo de elaboração ${ }^{12}$. Verifica-se, sob essa perspectiva, que a utilização da revisão integrativa se dá não somente para o desenvolvimento de políticas, protocolos e/ou procedimentos, mas influi também no pensamento crítico acerca de práticas cotidianas $^{13}$.

Num primeiro momento, foi feito o levantamento dos estudos sobre o lúdico na classe hospitalar disponíveis online entre o $2^{\circ}$ semestre de 2015 e segundo semestre de 2017. As ferramentas de busca utilizadas foram: Google Acadêmico, SCIELO e Plataforma da Capes. Optou-se por essas bases pelo alto alcance em acervos sobre o tema.

Foram utilizados os seguintes descritores: lúdico na classe hospitalar, lúdico na pedagogia hospitalar e brinquedoteca hospitalar. Tais descritores foram escolhidos por serem nomenclaturas utilizadas para se referir ao lúdico no ambiente da classe hospitalar, e deveriam apresentar-se nos títulos e/ou resumos.

Devido ao baixo número de periódicos encontrados a partir de uma análise inicial, foram considerados artigos científicos publicados em revistas eletrônicas de cunho nacional e internacional, artigos apresentados em anais de simpósios e que foram publicados na íntegra, bem como monografias, dissertações e teses.

Foram adotados os seguintes critérios para seleção dos estudos: além da presença dos descritores, todos os tipos de estudos (original, revisão de literatura, relato de experiência, e outros) com resumos e textos completos disponíveis para análise e publicados no idioma português, uma vez que pretendia-se verificar o contexto nacional.

0 recurso utilizado na coleta foi a ferramenta "termo exato", em consonância com os descritores elencados. Dessa seleção, os estudos tiveram seus conteúdos lidos e 
analisados com base na Análise de RESULTADOS

Conteúdo14, criando-se, a partir daí, A respeito do lúdico na classe hospitalar, categorias que representassem o conjunto das foram encontrados para análise 16 estudos. produções.

Revelou-se que os estudos estão concentrados, sem maiores discrepâncias, nas diferentes regiões do país, sendo a região norte a detentora do maior número de publicações, conforme o Quadro 1.

Quadro 1. Publicações de artigos sobre a temática do Lúdico no ambiente hospitalar por região de publicação. Araçatuba/SP, 2018.

\begin{tabular}{|l|c|}
\hline Região & Número de estudos \\
\hline Norte & 4 \\
\hline Nordeste & 2 \\
\hline Centro-Oeste & 2 \\
\hline Sudeste & 3 \\
\hline Sul & 2 \\
\hline Publicações internacionais & 3 \\
\hline
\end{tabular}

Em relação ao ano das publicações, foi número de publicações, conforme demonstra constatado que o ano de 2016 obteve o maior o Gráfico 1.

Gráfico 1. Ano de publicação de artigos sobre a temática do Lúdico no ambiente hospitalar. Araçatuba/SP, 2018.

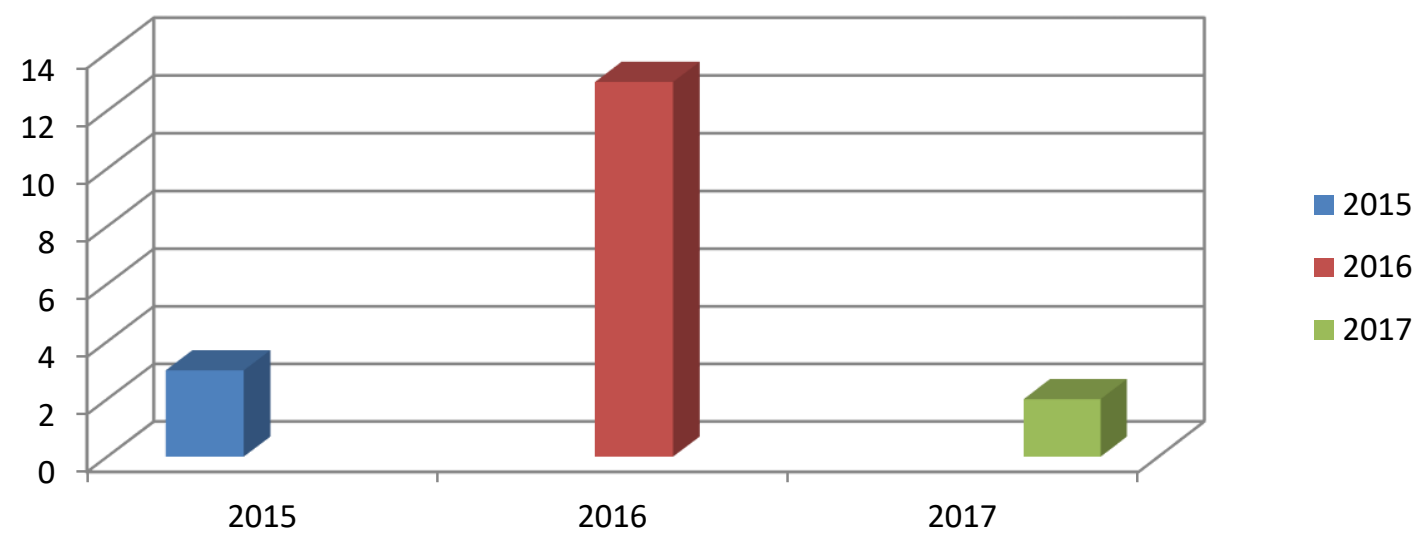

De acordo com o material levantado, as modalidades de estudo se configuraram da seguinte forma: nove artigos científicos publicados em revistas eletrônicas, três artigos publicados em anais de eventos, duas monografias de final de curso e uma dissertação de mestrado.

Em posse do material encontrado, seguiram-se os procedimentos de leitura de cada estudo, com vistas a transformá-los num conjunto de informações significativas na experiência do processo pedagógico hospitalar, para agrupá-los em unidades de análise. Dessa maneira, foram criadas duas humanização na classe hospitalar e o lúdico como processo de aprendizagem no ambiente da classe hospitalar.

\section{DISCUSSÃO}

O lúdico como processo de humanização na classe hospitalar

Os 7 trabalhos que compõem essa categoria tratam de temas que refletem a experimentação do lúdico como fonte de inclusão e humanização dos sujeitos que frequentam a classe hospitalar ao longo do seu processo de internação, conforme demonstra o Quadro 2. 
Quadro 2. Publicações da categoria - O lúdico como processo de humanização na classe. Araçatuba, 2018.

\begin{tabular}{|c|c|c|c|c|}
\hline $\begin{array}{c}\text { Local de } \\
\text { publicação }\end{array}$ & Título & Objetivos & Métodos & Autor/Ano \\
\hline $\begin{array}{l}\text { Universidade } \\
\text { Estadual de } \\
\text { Londrina }\end{array}$ & $\begin{array}{c}\text { A inserção do lúdico no } \\
\text { ambiente hospitalar para } \\
\text { crianças e } \\
\text { adolescentes*** }\end{array}$ & $\begin{array}{c}\text { Analisar e descrever a } \\
\text { importância da } \\
\text { ludicidade no âmbito } \\
\text { hospitalar. }\end{array}$ & $\begin{array}{c}\text { Pesquisa bibliográfica e } \\
\text { exploratória. }\end{array}$ & $\begin{array}{l}\text { Nogueira } \\
2016\end{array}$ \\
\hline $\begin{array}{c}\text { Revista } \\
\text { Educativa }\end{array}$ & $\begin{array}{c}\text { Brincar e aprender em } \\
\text { hospitais: enfrentamento } \\
\text { da doença na infância* }\end{array}$ & $\begin{array}{l}\text { Verificar o papel da } \\
\text { brincadeira como } \\
\text { dispositivo pedagógico } \\
\text { no desenvolvimento da } \\
\text { criança hospitalizada. }\end{array}$ & $\begin{array}{c}\text { Observação não- } \\
\text { participante, } \\
\text { entrevistas registradas } \\
\text { em "diário de bordo". }\end{array}$ & $\begin{array}{c}\text { Silva, Silva } \\
2016\end{array}$ \\
\hline $\begin{array}{l}\text { XII Seminário } \\
\text { Jogos } \\
\text { eletrônicos, } \\
\text { Educação, } \\
\text { Comunicação }\end{array}$ & $\begin{array}{c}\text { Jogos digitais nas classes } \\
\text { hospitalares: } \\
\text { desbravando novas } \\
\text { interfaces** }\end{array}$ & $\begin{array}{c}\text { Apresentar } \\
\text { experiências que } \\
\text { integram os jogos } \\
\text { digitais nas atividades } \\
\text { realizadas nas classes } \\
\text { hospitalares. }\end{array}$ & $\begin{array}{l}\text { Relato de } \\
\text { Experiência. }\end{array}$ & $\begin{array}{l}\text { Neves, } \\
\text { Alves, } \\
\text { Gonzalez } \\
2016\end{array}$ \\
\hline $\begin{array}{l}\text { Revista } \\
\text { Sentidos da } \\
\text { Cultura }\end{array}$ & $\begin{array}{c}\text { O jogo da trilha } \\
\text { pedagógica na unidade } \\
\text { escolar abrigo João Paulo } \\
\text { II: sentidos da } \\
\text { aprendizagem nas inter- } \\
\text { relações pessoais e } \\
\text { inclusivas* }\end{array}$ & $\begin{array}{c}\text { Utilização de um } \\
\text { instrumento lúdico- } \\
\text { pedagógico no } \\
\text { desenvolvimento } \\
\text { cognitivo e social dos } \\
\text { alunos a partir dos } \\
\text { mitos que permeiam o } \\
\text { imaginário amazônico. }\end{array}$ & $\begin{array}{l}\text { Observação - } \\
\text { participante. }\end{array}$ & $\begin{array}{l}\text { Pombo } \\
2016\end{array}$ \\
\hline $\begin{array}{c}\text { Revista } \\
\text { Internacional } \\
\text { de } \\
\text { Organización } \\
\text { Educativa y } \\
\text { Liderazgo }\end{array}$ & $\begin{array}{c}\text { Pedagogia hospitalar: } \\
\text { pacientes de Ala } \\
\text { Psiquiátrica vivenciam } \\
\text { atividades lúdicas, } \\
\text { pedagógicas e } \\
\text { recreativas, a partir de } \\
\text { uma visão humanista que } \\
\text { contribui para uma } \\
\text { melhor qualidade de } \\
\text { vida* }\end{array}$ & $\begin{array}{c}\text { Investigar a } \\
\text { importância de os } \\
\text { pacientes vivenciarem } \\
\text { atividades lúdicas - } \\
\text { educativas. }\end{array}$ & $\begin{array}{l}\text { Pesquisa- } \\
\text { ação; pesquisa } \\
\text { bibliográfica e } \\
\text { observação- } \\
\text { participante. }\end{array}$ & $\begin{array}{l}\text { Costa } \\
2016\end{array}$ \\
\hline $\begin{array}{l}\text { Enfermagem } \\
\text { em foco }\end{array}$ & $\begin{array}{l}\text { Câncer infantil: vivências } \\
\text { de crianças em } \\
\text { tratamento oncológico* }\end{array}$ & $\begin{array}{l}\text { Conhecer a percepção } \\
\text { da criança em } \\
\text { tratamento oncológico } \\
\text { sobre a vivência da } \\
\text { doença. }\end{array}$ & $\begin{array}{l}\text { Estudo descritivo; } \\
\text { observacional. }\end{array}$ & $\begin{array}{l}\text { Silva, } \\
\text { Xavier, } \\
\text { Oliveira, } \\
2017\end{array}$ \\
\hline $\begin{array}{c}\text { Universidade } \\
\text { Regional } \\
\text { do } \\
\text { Noroeste do } \\
\text { Estado do Rio } \\
\text { Grande do Sul } \\
\end{array}$ & $\begin{array}{c}\text { As contribuições do } \\
\text { brincar em um ambiente } \\
\text { hospitalar*** }\end{array}$ & $\begin{array}{c}\text { Estudar as } \\
\text { contribuições do } \\
\text { brincar em um } \\
\text { ambiente hospitalar. }\end{array}$ & $\begin{array}{c}\text { Pesquisa bibliográfica; } \\
\text { aplicação de } \\
\text { questionário. }\end{array}$ & $\begin{array}{c}\text { Garbinatto } \\
2016\end{array}$ \\
\hline
\end{tabular}

* artigo publicado em revista eletrônica **artigo publicado em anais de eventos ***monografia ****dissertação

A compreensão do lúdico no ambiente da classe hospitalar tem como subsídio o entendimento acerca do processo na melhoria da saúde das crianças e adolescentes durante o tratamento através da ludicidade ${ }^{15}$. A brincadeira surge como dispositivo que auxilia as crianças a superarem as inconveniências de seu estado de saúde e a aproveitarem melhor o período do tratamento, criando vínculos pelo ato de brincar e maior abertura para experiências educativas, tornando a permanência no hospital mais agradável e descontraída ${ }^{16}$.

Um dos estudos traz os jogos digitais como forma de proporcionar vivências lúdicas e os textos afirmam que, com base nos relatos dos pacientes, as experiências com esses jogos proporcionam sensações boas e de prazer, 
amenizando a angústia, a ansiedade, a tristeza e o isolamento causados durante o período de internação ${ }^{17}$.

$\mathrm{O}$ atendimento para o público da Educação de Jovens e Adultos (EJA) no contexto da classe hospitalar destaca-se não só pela sua relevância, mas também por propiciar o atendimento pedagógico para todos. Dessa forma, o jogo da trilha é apontado como uma metodologia que estimula de forma prazerosa e motivadora a partilha de conhecimentos. Além de ser um jogo com características específicas, há também os vínculos que se estabelecem entre as equipes ${ }^{18}$.

Os projetos de humanização em hospitais que envolvem a presença dos pedagogos nesse ambiente estão contribuindo para uma melhor qualidade de vida dos pacientes, inserindo a arte, o lúdico, o movimento e a vida nos hospitais. Isso vem trazendo resultados surpreendentes, como aponta um dos textos analisados ${ }^{19}$.

Outro tema tratado na questão da humanização nos trabalhos levantados diz respeito ao diagnóstico de câncer e consequente hospitalização, o que culmina em privações no mundo da criança, que se vê restrita, principalmente nas ações de brincar ${ }^{20}$. As atividades lúdicas desenvolvidas na classe hospitalar expressam, sobretudo por meio do brincar, melhorias na adesão ao tratamento.

A pesquisa sobre a importância do brincar em um ambiente hospitalar ${ }^{21}$ considera que as práticas lúdicas manifestadas no ato de brincar representam a própria vida da criança. A dimensão lúdica precisa estar presente em quaisquer lugares, incluindo a classe hospitalar, pois é por meio do brincar que a criança se desenvolve, se reconhece e assimila a realidade. Dessa forma, tais fatores não ficarão de fora, mesmo a criança estando hospitalizada.

Percebe-se, dessa forma, que os achados que compreendem essa categoria viabilizam o brincar como forma de humanizar, criando um mundo no qual vale a pena viver novas perspectivas, especialmente no que se refere ao status de paciente das crianças e adolescentes hospitalizados. Isto é, o lúdico se configura, nesse sentido, como o campo da arte da interlocução, o que faz com que o paciente silenciado escape das amarras de coadjuvante da sua rotina de conformação e, partindo dessa premissa, torne-se o ator principal ${ }^{8}$.

Também verificou-se, no impacto ocasionado pelo brincar de "faz de conta" no contexto hospitalar, os outros como pessoas completas, inclusive, por meio das falas dos médicos, enfermeiros, pais e das próprias crianças. Essas falas dizem respeito às expressões minuciosas de um brincar que ameniza as tensões desse ambiente, oferecendo aos sujeitos hospitalizados a oportunidade de se tornarem atuantes, apesar da enfermidade que possuem ${ }^{22}$.

Os estudos que compõem essa categoria trazem a possibilidade de reordenar os sentidos e significados marcados pela dor e pela angústia, abrindo espaço para a confiança recíproca e para o debate gratificante realizado com amor. Sem sombra de dúvidas, um ambiente cercado de sorrisos e sentimentos reflete na melhora do estado clínico dos educandos hospitalizados.

Os estudos apresentam que o lúdico, ao se instalar nesse ambiente, alivia a rotina hospitalar (aquela repleta de exames clínicos e outros procedimentos) quando se percebe $o$ envolvimento dos enfermos nas atividades.

Tais ações com intencionalidade pedagógica promovem o direito à liberdade de conhecer o mundo que está à sua volta, de brincar pela alegria do brincar, atuando, dessa forma, como aliviador da ansiedade e, ao mesmo tempo, atendendo a necessidades emocionais e afetivas por meio do contato físico, contribuindo diretamente na recuperação da criança.

Lúdico como processo de aprendizagem no ambiente da classe hospitalar

Nesta categoria foram selecionados os estudos que discutem aspectos que versam sobre a prática lúdica aliada ao processo de aprendizagem no contexto da classe hospitalar. Enquadraram-se, nessa categoria, 9 estudos, distribuídos no Quadro 3. 
Quadro 3. Publicações da categoria - O Lúdico como processo de aprendizagem no ambiente da classe hospitalar. Araçatuba/SP, 2018.

\begin{tabular}{|c|c|c|c|c|}
\hline $\begin{array}{c}\text { Local de } \\
\text { publicação }\end{array}$ & Título & Objetivo & Métodos & $\begin{array}{c}\text { Autor/ } \\
\text { Ano }\end{array}$ \\
\hline $\begin{array}{l}\text { Universidade } \\
\text { Federal do } \\
\text { Mato Grosso }\end{array}$ & $\begin{array}{c}\text { O papel do jogo nos } \\
\text { processos de aprendizagem } \\
\text { de crianças } \\
\text { hospitalizadas**** }\end{array}$ & $\begin{array}{l}\text { Compreender o papel do } \\
\text { jogo, situando-o como } \\
\text { elemento mediador nos } \\
\text { processos de aprendizagem } \\
\text { em crianças hospitalizadas. }\end{array}$ & $\begin{array}{c}\text { Entrevista } \\
\text { semiestruturada; } \\
\text { observação- } \\
\text { participante; } \\
\text { análise } \\
\text { documental }\end{array}$ & $\begin{array}{l}\text { Alves } \\
2015\end{array}$ \\
\hline $\begin{array}{l}\text { Universidade } \\
\text { Federal do } \\
\text { Rio Grande } \\
\text { do Norte }\end{array}$ & $\begin{array}{c}\text { O brincar no contexto } \\
\text { hospitalar e sua relevância } \\
\text { na aprendizagem infantil }\end{array}$ & $\begin{array}{l}\text { Verificar a contribuição do } \\
\text { brincar no processo de } \\
\text { aprendizagem infantil no } \\
\text { contexto hospitalar. }\end{array}$ & $\begin{array}{l}\text { Pesquisa } \\
\text { exploratória; } \\
\text { entrevista } \\
\text { estruturada }\end{array}$ & $\begin{array}{l}\text { Batista } \\
2016\end{array}$ \\
\hline $\begin{array}{c}\text { Centro } \\
\text { Universitário } \\
\text { Jorge Amado }\end{array}$ & $\begin{array}{c}\text { A influência do lúdico no } \\
\text { processo de } \\
\text { desenvolvimento- } \\
\text { aprendizagem de crianças } \\
\text { hospitalizadas* }\end{array}$ & $\begin{array}{c}\text { Analisar a influência da } \\
\text { ludicidade no processo de } \\
\text { aprendizagem de crianças } \\
\text { hospitalizadas. }\end{array}$ & $\begin{array}{l}\text { Observação } \\
\text { sistemática; } \\
\text { análise } \\
\text { documental }\end{array}$ & $\begin{array}{c}\text { Conceição } \\
2017\end{array}$ \\
\hline $\begin{array}{c}\text { Revista } \\
\text { Farociência }\end{array}$ & $\begin{array}{l}\text { O lúdico na educação das } \\
\text { crianças hospitalizadas* }\end{array}$ & $\begin{array}{l}\text { Desenvolver uma pesquisa } \\
\text { sobre o lúdico na educação } \\
\text { das crianças hospitalizadas. }\end{array}$ & $\begin{array}{c}\text { Pesquisa } \\
\text { bibliográfica; } \\
\text { questionário } \\
\text { semiestruturado }\end{array}$ & $\begin{array}{l}\text { Rocha, } \\
\text { Porfiro } \\
2015\end{array}$ \\
\hline $\begin{array}{l}\text { ARTEFACTU } \\
\text { M } \\
\text { Estudos em } \\
\text { Linguagens e } \\
\text { Tecnologia } \\
\end{array}$ & $\begin{array}{c}\text { Tablets na pedagogia } \\
\text { hospitalar: reflexões e } \\
\text { possibilidades de uso numa } \\
\text { brinquedoteca* }\end{array}$ & $\begin{array}{c}\text { Descrever o uso do tablet } \\
\text { numa perspectiva escolar e } \\
\text { não escolar da Pedagogia } \\
\text { Hospitalar. }\end{array}$ & $\begin{array}{c}\text { Pesquisa } \\
\text { bibliográfica }\end{array}$ & $\begin{array}{l}\text { Sousa, } \\
\text { Pinel, } \\
\text { Louzada } \\
2016\end{array}$ \\
\hline $\begin{array}{c}\text { SIMEDUC } \\
\text { Simpósio } \\
\text { Internacional } \\
\text { de Educação } \\
\text { e } \\
\text { Comunicação } \\
\end{array}$ & $\begin{array}{c}\text { A inclusão das mídias como } \\
\text { estratégia da pedagogia } \\
\text { hospitalar** }\end{array}$ & $\begin{array}{l}\text { Apresentar estudos sobre a } \\
\text { inclusão das mídias nos } \\
\text { processos de ensino - } \\
\text { aprendizagem de crianças e } \\
\text { adolescentes internados em } \\
\text { hospitais. }\end{array}$ & $\begin{array}{l}\text { Revisão } \\
\text { bibliográfica, } \\
\text { análise } \\
\text { documental }\end{array}$ & $\begin{array}{l}\text { Fontes } \\
2016\end{array}$ \\
\hline $\begin{array}{c}\text { WIE } \\
\text { Workshop } \\
\text { de } \\
\text { informática } \\
\text { na escola } \\
\end{array}$ & $\begin{array}{c}\text { Brincando e aprendendo: um } \\
\text { a proposta lúdica de inclusão } \\
\text { social e digital para pacientes } \\
\text { de serviços de Oncologia } \\
\text { Pediátrica** } \\
\end{array}$ & $\begin{array}{c}\text { Apresentar } \\
\text { a utilização de jogos online e } \\
\text { m articulação com os } \\
\text { conteúdos trabalhados em } \\
\text { uma classe hospitalar. }\end{array}$ & $\begin{array}{l}\text { Observação- } \\
\text { participante. }\end{array}$ & $\begin{array}{l}\text { Santos, } \\
\text { Santos, } \\
\text { Gomes } \\
2016\end{array}$ \\
\hline $\begin{array}{l}\text { Revista da } \\
\text { Fundação } \\
\text { Vida Cristã }\end{array}$ & $\begin{array}{c}\text { O brincar de crianças com } \\
\text { doenças crônicas } \\
\text { hospitalizadas* }\end{array}$ & $\begin{array}{l}\text { Descrever o brincar de } \\
\text { crianças com doenças } \\
\text { crônicas hospitalizadas. }\end{array}$ & $\begin{array}{c}\text { Aplicação da } \\
\text { Escala Lúdica } \\
\text { Pré-Escolar de } \\
\text { Knox. }\end{array}$ & $\begin{array}{c}\text { Grigolatto, } \\
\text { Sposito, } \\
\text { Panúncio, } \\
\text { Pinto } \\
2016 \\
\end{array}$ \\
\hline $\begin{array}{l}\text { Revista } \\
\text { Conexão }\end{array}$ & $\begin{array}{l}\text { As concepções de } \\
\text { acadêmicos sobre práticas } \\
\text { lúdicas em um projeto de } \\
\text { extensão em hemocentro* }\end{array}$ & $\begin{array}{l}\text { Apresentar as concepções } \\
\text { de acadêmicos do curso de } \\
\text { Pedagogia e de Educação } \\
\text { Física sobre os desafios e as } \\
\text { reflexões de um Projeto de } \\
\text { Extensão que é } \\
\text { desenvolvido em um } \\
\text { Hemocentro do interior do } \\
\text { Paraná. }\end{array}$ & $\begin{array}{c}\text { Pesquisa de } \\
\text { intervenção, } \\
\text { questionários } \\
\text { semiestruturados }\end{array}$ & $\begin{array}{l}\text { Paula, } \\
\text { Silva, } \\
\text { Silva, } \\
\text { Rodrigues } \\
2016\end{array}$ \\
\hline
\end{tabular}

Considera-se a classe hospitalar e a brinquedoteca como espaços de aprendizagem, lazer e desenvolvimento, sendo o jogo o precursor e mediador de diversos processos entre as pessoas, em especial os educandos hospitalizados que os frequentam. Tais ambientes favorecem 0 desenvolvimento de vínculos, a aprendizagem 
de regras, o alcance de novas experiências e o enfrentamento das situações de doença e hospitalização ${ }^{23}$.

0 brincar contribui de forma significativa na aprendizagem infantil, colaborando com os procedimentos próprios do ambiente hospitalar e envolvendo a criança hospitalizada no universo das aprendizagens escolares ${ }^{24}$. Constatou-se que o lúdico influencia positivamente no processo de desenvolvimento e aprendizagens socioculturais de crianças que se encontram internadas, além de se configurar como facilitador para adaptações à rotina hospitalar, bem como na adesão ao tratamento e no decorrer das atividades da classe hospitalar ${ }^{25}$.

O lúdico na educação das crianças hospitalizadas se mostra importante tanto para a recuperação quanto para o processo de ensino e aprendizagem ${ }^{26}$. Numa tese publicada em $2014^{27}$, desvelou-se possíveis sentidos da potência do tablet (e afins) no desenvolvimento e aprendizagem das pessoas inseridas numa brinquedoteca. Esses dispositivos são apontados como facilitadores da aprendizagem na pedagogia hospitalar escolar.

Outros dois estudos também apontam que o uso do tablet vem ganhando, cada vez mais, novos contornos do humano, ou seja, sua finalidade depende das formas de uso, pois é "coisa objetal" e, sendo assim, se configura como mobilizador de conhecimento no processo de aprendizagem na classe hospitalar ${ }^{28,29}$, o que confirma a potencialidade do uso de tablets e jogos digitais como fontes lúdicas no processo de aprendizagem para alunos hospitalizados.

A utilização da Escala Lúdica Pré-Escolar de Knox (revisada e adaptada culturalmente para o Brasil) apresenta a existência de defasagem no comportamento lúdico (brincar) das crianças hospitalizadas, sendo importante, portanto, a estimulação lúdica no ambiente da classe hospitalar como tentativa de minimizar os sintomas da patologia e os efeitos negativos da hospitalização ${ }^{30}$.

Um projeto de extensão em parceria dos cursos de Pedagogia e Educação Física com o Hemocentro e a classe hospitalar é o foco de outro estudo. Ele aponta para o fato de que práticas lúdicas possibilitam melhores interações entre os pacientes, num processo de ensino e de aprendizagem mútuos, ao mesmo tempo em que se dá um novo sentido às suas práticas ${ }^{31}$.

Em linhas gerais, as atividades lúdicas perpassam as memórias sociais e artísticas da história da humanidade, exercendo uma função importante no desenvolvimento cognitivo, motor, social, afetivo, emocional, físico e cultural. 0 processo pelo qual se constitui o conhecimento passa pela dimensão da ludicidade, uma vez que no jogo ou na brincadeira, a criança cria e recria conhecimento ${ }^{32}$.

Ao conciliar a educação sistematizada com a classe hospitalar, o professor deve perceber que sua atuação vai além daquelas preconizadas e estabelecidas legalmente pela sua formação. Ou seja, no ambiente hospitalar a dimensão da humanidade detém um grande valor pedagógico, pois torna o ambiente aconchegante, divertido e prazeroso, transformando-o num espaço que possibilita o processo de aprendizagem.

Apesar disso, há carência no uso de atividades lúdicas ${ }^{8,22}$. Por esse motivo, essas atividades são sugeridas como forma de amenizar as consequências negativas advindas da internação. 0 uso de brinquedos e brincadeiras deve ser considerado um facilitador nas questões pedagógicas dos conteúdos escolares, sobretudo na aprendizagem infantil.

Os achados que compõem essa categoria mostram que o caminho do lúdico como facilitador da aprendizagem na classe hospitalar está trilhando, cada vez mais, um sentido de construções de atividades que promovam, além das questões de conteúdo, a possibilidade de acesso ao meio digital, uma vez que a linguagem digital faz parte das vidas dessas crianças, mesmo que hospitalizadas, podendo, dentro dessa perspectiva, alterar seus padrões de pensamento e a forma como pensam, agem e aprendem ${ }^{33}$.

\section{CONCLUSÃO}

Como limitação do estudo tem-se a temporalidade considerada. Apesar disso, 
verificou-se que os estudos são divulgados, em grande parte, por meio de artigos científicos que estão publicados online, e também apresentados em simpósios, e o número de dissertações e teses de doutorado sobre o tema foi pequeno.

É necessário que haja maior visibilidade dessa temática no âmbito das universidades, inclusive nos programas de pós-graduação, uma vez que, quanto mais locais considerarem as questões do lúdico no contexto da classe hospitalar como área de pesquisa científica e educativa, maiores serão as chances de atribuir um sentido humanizado e pedagógico a esses ambientes hospitalares, bem como maior será o número de produções e melhores serão as contribuições para a área.

Considera-se a classe hospitalar e as brinquedotecas como espaços altamente atrativos e com enorme potencial na humanização para as crianças e adolescentes hospitalizados, já que eles passam a maior parte do tempo angustiados pelo processo de internação. Logo, qualquer local onde existam espaços para brincar, jogar e interagir se torna atrativo e humanizador.

As professoras que ministram aulas em classes hospitalares podem, seguramente, utilizar os espaços da brinquedoteca para trabalhar em conjunto no desenvolvimento de atividades que tornem possível criar situações nas quais, recorrendo ao lúdico, os educandos hospitalizados possam resolver os problemas impostos.

Isso pode levar à superação do ensino tradicional e instrucional, além de integrar, por meio de atividades lúdicas e pedagógicas, diversas possibilidades, apresentando outra maneira de dar continuidade à vida escolar do estudante hospitalizado.

\section{REFERÊNCIAS}

1. Fontes RS. Da classe à pedagogia hospitalar: a educação para além da escolarização. Linhas. [Internet]. 2008 [citado em 10 set 2018]; 9(1):72-92. Disponível em: http://www.periodicos.udesc.br/index.php/l inhas/article/viewFile/1395/1192

2. Rodrigues JC, Simões RMR. Nuances acerca da rotina de uma classe hospitalar: um estudo de caso. Evidência. [Internet]. 2018 [citado em 05 nov 2018]; 14(14):193-202. Disponível em:

https://www.uniaraxa.edu.br/ojs/index.php/evid encia/article/view/582

3. Ferreira EA, Vargas IMA, Rocha SMM. Um estudo bibliográfico sobre o apego mãe e filho: bases para a assistência de enfermagem pediátrica e neonatal. Rev Latinoam Enferm. [Internet]. 1998 [citado em 11 nov 2018]; 6, (4):111-6. Disponível em: http://www.revistas.usp.br/rlae/article/vie $\mathrm{w} / 1327 / 1353$

4. Oliveira TC. Um breve histórico sobre as classes hospitalares no Brasil e no mundo. In: XI Congresso Nacional de educação/EDUCERE, II Seminário Internacional de Representações Sociais, Subjetividade e Educação, IV Seminário Internacional sobre profissionalização docente [Internet]; 2013; Curitiba. Curitiba: PUCPR; 2013 [citado em 05 set 2018]. Disponível em: http://educere.bruc.com.br/ANAIS2013/pdf /9052_5537.pdf

5.Batista CA. A classe hospitalarno Brasil e o papel do profissional docente. [Monografia]. São Paulo, SP: IFSP; 2014. 43p.

6. Fonseca ES. Atendimento escolar no ambiente hospitalar. In: Conferência Internacional Saberes para uma Cidadania Planetária [Internet]; 2016; Fortaleza. Fortaleza: UECE; 2016 [citado em 14 jul 2018]. Disponível em: http://uece.br/eventos/spcp/anais/trabalho s_completos/247-38396-27032016-

112411.pdf

7.Santos SMP. Brinquedoteca: o lúdico em dif erentes contextos. Petrópolis, RJ: Vozes; 1997. 8. Rodrigues JC, Simões RMR. O corpo entre o riso e o choro na classe hospitalar. [Dissertação]. Uberaba, MG: Universidade Federal do Triângulo Mineiro; 2016. 96p.

9. Cardoso MR. Desafios e possibilidades da ludicidade no atendimento pedagógico hospitalar. [Dissertação]. Brasília, DF. Universidade de Brasília; 2011. 136p.

10. Vigotsky LS. A formação social da mente. São Paulo: Martins Fontes; 1984. 
11. Kishimoto TM, organizador. Jogo, brinquedo, brincadeira e a educação. 7ed. São Paulo: Cortez, 2003.

12. Ganong LH. Integrative reviews of nursing research. Res Nurs Health. 1987; 10(1):1-11. 13. Stetler CB, Morsi D, Rucki S, Broughton S, Corrigan B, Fitzgerald J, et al. Utilizationfocused integrative reviews in a nursing service. Appl Nurs Res. [Internet]. 1998 [citado em 14 jul 2018]; 11(4):195-206. Disponível em: https://www.sciencedirect.com/science/arti cle/pii/S0897189798803297

14. Moraes R. Análise de conteúdo. Rev Educ. (Porto Alegre). 1999; 22, (37):7-32.

15. Nogueira AC. A inserção do lúdico no ambiente hospitalar para crianças e adolescentes. [Trabalho de Conclusão de Curso]. Natal, RN. Universidade Federal do Rio Grande do Norte; 2016. 127p.

16. Silva MB, Almeida AO. Brincar e aprender em hospitais: enfrentamento da doença na infância. Educativa. [Internet]. 2016 [citado em 05 jul 2018]; 19(1):33-51. Disponível em: http://seer.pucgoias.edu.br/index.php/educ ativa/article/view/5014

17. Neves IBC, Alves L, Gonzalez C. Jogos digitais nas classes hospitalares: desbravando novas interfaces. Rev UNEB. 2016:52-60.

18. Pombo DP, Fontes AR. 0 jogo da trilha pedagógica na unidade escolar Abrigo João Paulo II: sentidos da aprendizagem nas interrelações pessoais e inclusivas. Sentidos da Cultura. [Internet]. 2017 [citado em 05 jul 2018]; 2(3):39-44. Disponível em: https://paginas.uepa.br/seer/index.php/sen tidos/article/view/1027/670

19. Costa GMT. Pedagogia hospitalar: pacientes de ala psiquiátrica vivenciam atividades lúdicas, pedagógicas e recreativas, a partir de uma visão humanista que contribui para uma melhor qualidade de vida. Rev Intern Organiz Educ Liderazgo. [Internet]. 2016 [citado em 19 jan 2018]; 2(2):96-112. Disponível

em: https://journals.epistemopolis.org/index.ph p/liderazgo/article/view/939/504

20. Silva PLN, Xavier GC, Oliveira VV, Figueredo ML, Prado PF, Aguiar Filho W. Câncer infantil: vivências de crianças em tratamento oncológico. Enferm Foco.
[Internet]. 2017 [citado em 25 ago 2018]; 7(3/4):51-5. Disponível em: http://revista.cofen.gov.br/index.php/enfer magem/article/view/916/346

21. Garbinatto AMF. As contribuições do brincar em um ambiente hospitalar [Internet] [Trabalho de Conclusão de Curso]. Santa Rosa, RS: Universidade Regional do Noroeste do Estado do Rio Grande do Sul; 2016 [citado em 25 ago 2018]. Disponível em: http://bibliodigital.unijui.edu.br:8080/xmlui /handle/123456789/3757

22. Bomtempo E, Antunha EG, Oliveira, VB, organizadoras. Brincando na escola, no hospital, na rua... Rio de Janeiro: Wak; 2006. $192 \mathrm{p}$.

23. Alves PP. O papel do jogo nos processos de aprendizagem de crianças hospitalizadas. [Dissertação]. Cuiabá, MT: Universidade Federal do Mato Grosso; 2015. 142p.

24. Batista MT. O brincar no contexto hospitalar e sua relevância na aprendizagem infantil. [Trabalho de Conclusão de Curso]. Natal, RN. Universidade Federal do Rio Grande do Norte; 2016. 36p.

25. Gonzaga PMA, Resende JWR, Passos VOA, Simões PRF. A influência da ludicidade para a aprendizagem de crianças em regime de internação hospitalar. REVASF [Internet]. 2017 [citado em 19 jan 2018]; 6(11):125-45. Disponível

em:

http://www.periodicos.univasf.edu.br/index. php/revasf/article/view/42

26. Rocha LL, Porfiro NA. O lúdico na educação das crianças hospitalizadas. Rev Farociencia. 2016; 2 (2):178-81.

27. Sousa CS, Pinel H, Louzada MC. Tablets na pedagogia hospitalar: reflexões e possibilidades de uso numa brinquedoteca. Artefactum. [Internet]. 2016 [citado em 19 jan 2018]; 13(2). Disponível em: http://artefactum.rafrom.com.br/index.php/ artefactum/article/view/1337/664

28. Fontes AR. A inclusão das mídias como estratégia da pedagogia hospitalar. In: 7응 Simpósio Internacional de Educação e Comunicação-SIMEDUC. 2016. [citado em 15 jan 2018]. Disponível em: http://eventos.set.edu.br/index.php/simedu c/article/view/3329 
29. Santos J, Santos AD, Gomes A. Brincando e aprendendo: uma proposta lúdica de inclusão social e digital para pacientes de serviços de Oncologia Pediátrica. In: XXII Workshop de Informática na Escola [Internet]. 2016. Uberlândia, MG; 2016 [citado em 15 jan 2018]. p.914-23. Disponível em http://www.brie.org/pub/index.php/wie/article/view/663 5

30. Grigolatto T, Sposito AM, Panúncio-Pinto MP, Pfeifer LI. O brincar de crianças com doenças crônicas hospitalizadas. Rev Ciên Saúde On-line. 2016 [citado em 12 jan 2019]; 1(1):8-16. Disponível em: http://revistaeletronicafunvic.org/index.php /c14ffd10/article/view/5/14

31. Paula EM, Silva MO, Silva LT, Santos MA, Rodrigues MOS. As concepções de acadêmicos sobre práticas lúdicas em um projeto de extensão em hemocentro. Rev Conexão UEPG. [Internet]. 2016 [citado em 25 set 2018];
12(3):448-60. Disponível em: http://www.revistas2.uepg.br/index.php/co nexao/article/view/9044

32. Bispo JNM. A ludicidade como motivação na aprendizagem. São Gonçalo [Internet]. [Trabalho de Conclusão de Curso]. São Gonçalo, RJ: Universidade do Estado do Rio de Janeiro; 2009 [citado em 25 set 2018]. Disponível em: http://www.ffp.uerj.br/arquivos/dedu/mon ografias/JNMB.2008.pdf

33. Prensky M. Digital native, digital immmigrants. On the horizon. 2001; 9(5):1-6.

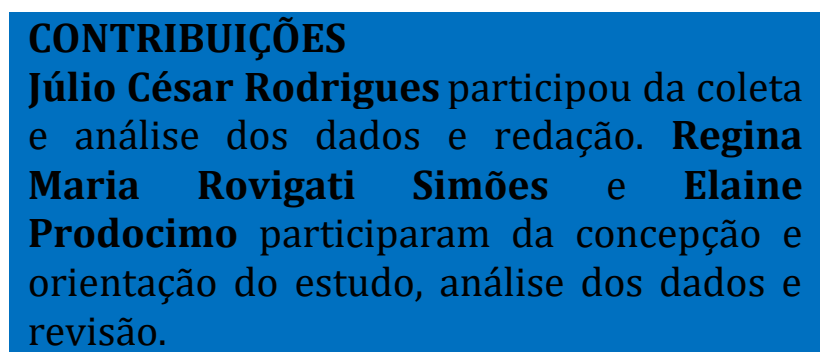

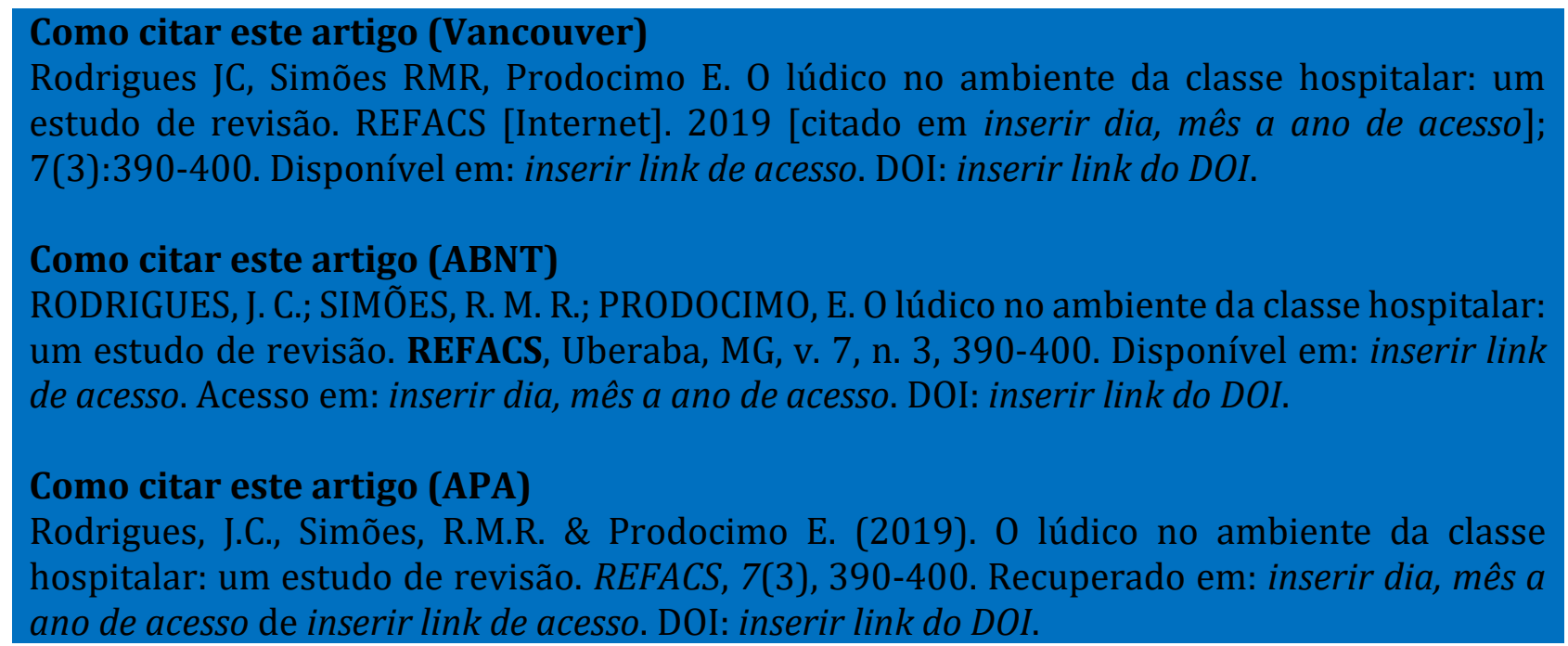

